\title{
Local fungus-specific Immunoglobulin E production in chronic rhinosinusitis with nasal polyps*
}

\author{
Yuji Ohki', Yoshitaka Okamoto', Tomohisa linuma', Heizaburo Yamamoto², \\ Takahito Toyotome3 ${ }^{3}$, Maki Yahiro', Syuji Yonekura', Daiju Sakurai', Katsuhiko \\ Kamei $^{4}$ \\ 'Department of Otolaryngology, Head and Neck Surgery, Chiba University Graduate School of Medicine, Chiba, Japan \\ 2 Division of Otolaryngology, Kimitsu Central Hospital, Kimitsu, Japan \\ ${ }^{3}$ Diagnostic Center for Animal Health and Food Safety, Obihiro University of Agriculture and Veterinary Medicine, Obihiro, Japan \\ ${ }^{4}$ Division of Clinical Research, Medical Mycology Research Center, Chiba University, Chiba, Japan
}

Rhinology 58: 2, $136-144,2020$

https://doi.org/10.4193/Rhin18.225

*Received for publication:

September 22, 2018

Accepted: November 20, 2019

\begin{abstract}
Background: Chronic rhinosinusitis with nasal polyps (CRSwNP) is a heterogeneous disease, and its pathogenesis remains controversial. This study aimed to examine the involvement of fungi in CRSwNP pathogenesis.

Methods: We enrolled 29 controls and 111 CRSwNP patients. We analyzed fungi in the nasal secretions, serum fungus-specific immunoglobulin E (IgE) levels, and nasal polyp (NP) IgE levels. Moreover, we evaluated the correlation between patients' IgE levels and computed tomography (CT) scores.
\end{abstract}

Results: There was no difference in fungal detection rate between CRSwNP patients with and without asthma. Specific IgEs against various antigens were highly detectable in NPs of CRSwNP patients. In CRSwNP patients, fungus-specific lgE levels in NPs were correlated with CT scores. Serum fungus-specific IgEs became undetectable after operation in more than half of the CRSwNP patients without asthma but not in those with asthma. Other serum airborne antigen-specific lgEs did not become undetectable after operation.

Conclusions: Fungus-specific lgEs were highly detectable in NPs of CRSwNP patients, and NPs comprised a major region of specific IgE production. Fungi may therefore play an important role in CRSwNP pathogenesis by inducing Th2 immune responses, including lgE synthesis.

Key words: chronic rhinosinusitits, nasal polyps, fungus-specific lgE, asthma

\section{Introduction}

Chronic rhinosinusitis (CRS) is a common chronic inflammatory disease of the sinonasal mucosa. CRS is considered a heterogeneous disease and is divided into two types according to the presence of nasal polyps (NPs). Chronic rhinosinusitis without nasal polyps (CRSsNP) is characterized by Th1-skewed inflammation, whereas chronic rhinosinusitis with nasal polyps (CRSwNP) is characterized by Th2-skewed inflammation ${ }^{(1,2)}$. Many factors, including microbes, superantigens, and allergens, have been implicated in CRS pathogenesis; however, the mechanism remains controversial.

Fungi are involved in chronic airway inflammation. According to
Matsuoka et al. ${ }^{(3)}$, Trichophyton-specific immunoglobulin E (IgE) may be associated with severe asthma. In the upper respiratory tract, fungi may cause allergic rhinitis and induce invasive fungal sinusitis and mycetoma. In recent years, fungi have been posited to cause various forms of chronic sinusitis by inducing an immune response to fungal colonization ${ }^{(4)}$. A recent study showed that total and specific lgEs, including fungus-specific lgEs in NPs, are associated with local eosinophilic inflammation ${ }^{(5)}$. However, double-blind placebo-controlled trials of the use of anti-fungal drugs in CRS patients have failed to show any benefits; thus, the role of fungi in CRS remains unclear ${ }^{(4)}$.

According to previous reports, CRSwNP comprises a heteroge- 
neous group of patients who differ with respect to co-existing asthma, allergies, NSAID-exacerbated respiratory diseases, smoking, and age of onset ${ }^{(6,7)}$. CRSwNP coexists with asthma in $17.8 \%-50 \%$ of the patients ${ }^{(8,9)}$. The presence of NPs is associated with the severity of asthma, regardless of the smoking status, and their incidence is $10 \%-30 \%$ in patients with mild asthma and $70 \%-90 \%$ in patients with severe asthma ${ }^{(6)}$. The histopathological features of CRSwNP and asthma largely overlap. Eosinophilic inflammation and airway remodeling occur in the mucosa of both CRSwNP and asthma patients ${ }^{(10,11)}$. Cytokine patterns in the sinus tissues of CRSwNP patients are similar to those in the bronchial tissues of asthma patients ${ }^{(12)}$. CRS and asthma can affect and amplify each other via a systemic route, which involves interleukin (IL)-5 and bone marrow ${ }^{(1)}$. The outcomes after endoscopic sinus surgery are significantly worse in CRSwNP patients with asthma than in CRSwNP patients without asthma ${ }^{(9,13,14)}$. Thus, the pathogenesis of CRSwNP with asthma may differ from that of CRSwNP without asthma.

In this study, we analyzed fungi in nasal secretions and specific $\mathrm{IgEs}$ in the serum and NPs of CRSwNP without asthma with and without asthma to evaluate the role of fungi in CRSwNP pathogenesis.

\section{Materials and methods}

\section{Patients}

We enrolled CRSwNP patients who underwent endoscopic sinus surgery at Chiba University Hospital and its affiliated hospitals (Kimitsu Chuo Hospital and the Chiba Otolaryngology Surgical Center) from December 2010 to January 2014 (Table 1). CRSwNP was diagnosed according to the criteria of the European Position Paper on Rhinosinusitis and Nasal Polyps ${ }^{(1)}$. Patients with allergic fungal sinusitis (AFRS) were excluded from this study. AFRS was diagnosed on the basis of the Bent-Kuhn criteria ${ }^{(15)}$. Subjects who did not present with sinusitis according to their CT findings were enrolled as controls. The protocol of the present study was approved by the ethics committee of each hospital, and written informed consent was obtained from all patients. No patient was treated with antibiotics and/or topical or systemic corticosteroids at least 1 month before operation.

Asthma and aspirin-intolerant asthma were diagnosed on the basis of medical history and results of physical examination. Atopic status was assessed on the basis of medical history and presence of specific IgEs (Japanese cedar pollen, cypress pollen, Alternaria, Aspergillus, Candida, Cladosporium, Penicillium, Trichophyton, or mites), as detected using the ImmunoCAP Kit (Phadia AB, Uppsala, Sweden). Six fungus-specific IgEs (against major airborne fungi) were quantified. The presence of at least one fungus-specific IgE in the serum was regarded as positivity for fungus-specific IgEs. Blood eosinophil counts were obtained as the percentage of eosinophils in whole blood. Tissue eosinophils in a high-power field (HPF) were counted in blinded manner by two observers. All patients underwent $C T$, and the $C T$ findings were evaluated using the Lund-Mackay scoring system ${ }^{(16)}$.

\section{Analyses of serum and local IgE}

For serum IgE analysis, we enrolled controls ( $n=29)$, CRSwNP patients with asthma $(n=40)$, and CRSwNP patients without asthma $(n=71)$ from each hospital. We tested for lgEs in the NPs of CRSwNP patients with $(n=24)$ and without $(n=48)$ asthma from whom a sufficient quantity of NPs could obtained during the operation. For local lgE analysis, controls $(n=5)$ who underwent septoplasty and turbinectomy were enrolled. Levels of total and specific lgEs in the NPs and turbinate mucosa were measured using the ImmunoCAP Kit, as described previously $(17,18)$. NPs were weighed and homogenized on ice with a power homogenizer (As One, Osaka, Japan). Phosphate-buffered saline (PBS, $1 \mathrm{~mL}$ ) was added for every $100 \mathrm{mg}$ of tissue. Aprotinin and leupeptin were added as protease inhibitors (Roche, Mannheim, Germany). The suspensions were centrifuged at $4000 \mathrm{rpm}$ for 10 min at $4^{\circ} \mathrm{C}$. Total and specific lgE [against Alternaria, Aspergillus, Candida, Cladosporium, Penicillium, Trichophyton, staphylococcal enterotoxin B (SEB), and mites] levels in the serum and NPs were determined using the ImmunoCAP Kit. The lower detection levels of $\lg E$ were $0.34 \mathrm{UA} / \mathrm{ml}$ and $1 \mathrm{UA} / \mathrm{g}$ in the serum and NPs, respectively. The cut-off value for positive serum lgE levels was $0.34 \mathrm{UA} / \mathrm{ml}$. We evaluated the correlations of total and specific IgE levels with CT scores.

\section{Assessment of fungal culture from nasal secretions} Fungal cultures were performed at the Medical Mycology Research Center at Chiba University. CRSwNP patients with (n $=20)$ and without $(n=34)$ asthma who underwent operations at Chiba University Hospital and control patients $(n=24)$ were assessed. Nasal secretions were aspirated from the nasal cavity into a sterile tube. If the secretion volume was low, PBS was injected into each side of the nasal cavity and aspirated into a sterile tube. The secretion sample was homogenized with $10 \%$ dithiothreitol ( $\mathrm{vol} / \mathrm{vol}$ ), and the mixture was incubated at room temperature for $15 \mathrm{~min}$. The samples were centrifuged at 8000 rpm for $10 \mathrm{~min}$ at $4^{\circ} \mathrm{C}$, and supernatants were removed. After the addition of $1 \mathrm{~mL}$ PBS with chloramphenicol $(0.05 \mathrm{~g} / \mathrm{L})$, the pellets were thoroughly vortexed and used for cultures to identify fungal species. Nasal secretion samples were plated on a growth medium (potato-dextrose-agar supplemented with chloramphenicol and CHROMagar Malassezia Candida), and the plates were incubated for up to 2 weeks at $25^{\circ} \mathrm{C}$. We used resulting colonies for the identification of fungal species via macroscopic and microscopic observations, followed by PCR ${ }^{(19)}$. For PCR, DNA was extracted from the other half of the nasal secretion samples using the EZ-EXTRACT for DNA/RNA Kit (AMR, Gifu, Japan); PCR was performed using PrimeSTAR polymerase (TaKaRa Biotechnology, Dalian) in accordance with the manufacturer's instructions. 
Table 1. Patient characteristics.

\begin{tabular}{|c|c|c|c|c|}
\hline & \multirow[t]{2}{*}{ Control } & \multicolumn{2}{|c|}{ CRSwNP $(n=111)$} & \multirow[t]{2}{*}{ p-value* } \\
\hline & & Without asthma & With asthma & \\
\hline Patients (n) & 29 & 71 & 40 & \\
\hline $\operatorname{Age}^{* *}$ & $37 \pm 2.0$ & $55 \pm 2.0$ & $58 \pm 2.7$ & \\
\hline Male/female (n) & $19 / 10$ & $52 / 19$ & $24 / 16$ & \\
\hline Aspirin intolerance (n) & 0 & 0 & 5 & $<0.05$ \\
\hline Atopic/non-atopic status (n) & $23 / 6$ & $44 / 27$ & $28 / 12$ & 0.395 \\
\hline Blood total lgE level $(\mathrm{IU} / \mathrm{ml})^{* *}$ & $121 \pm 38$ & $296 \pm 61$ & $464 \pm 80$ & 0.001 \\
\hline CT score (Lund-Mackay) ${ }^{* *}$ & 0 & $13 \pm 0.8$ & $18 \pm 0.9$ & $<0.001$ \\
\hline Blood eosinophil count $(/ \mathrm{mm} 3)^{* *}$ & $307 \pm 113$ & $270 \pm 22$ & $553 \pm 53$ & $<0.001$ \\
\hline Tissue eosinophil count (/HPF) & - & $86 \pm 16$ & $129 \pm 18$ & $<0.001$ \\
\hline Analysis of serum $\lg E(n)$ & 29 & 71 & 40 & \\
\hline Analysis of local lgE (n) & 5 & 48 & 24 & \\
\hline Analysis of fungal culture (n) & 24 & 34 & 20 & \\
\hline
\end{tabular}

CRSwNP: Chronic rhinosinusitis with nasal polyps; CT: Computed tomography; HPF: High-power field; IgE: Immunoglobulin E; * without asthma vs. with asthma; ${ }^{* *}$ mean \pm SD.

Table 2. Serum fungus-specific lgE levels.

\begin{tabular}{|c|c|c|c|c|}
\hline & \multirow[t]{2}{*}{ Control } & \multicolumn{2}{|c|}{ CRSwNP $(n=111)$} & \multirow[t]{2}{*}{ p-value* } \\
\hline & & Without asthma & With asthma & \\
\hline Patients (n) & 29 & 71 & 40 & \\
\hline Fungal-specific lgE in serum $\quad(\geq 0.34 / \mathrm{ml})(\mathrm{n})$ & 1 & 14 & 11 & 0.346 \\
\hline \multicolumn{5}{|l|}{ Fungal-specific lgE levels in the serum $(\mathrm{UA} / \mathrm{ml})^{* *}$} \\
\hline Alternaria & & $0.9(n=1)$ & $0.80 \pm 0.30(n=5)$ & \\
\hline Aspergillus & & $2.50 \pm 0.71(n=4)$ & $5.01 \pm 2.85(n=10)$ & \\
\hline Candida & $0.41(n=1)$ & $2.64 \pm 0.93(n=11)$ & $1.28 \pm 0.13(n=7)$ & \\
\hline Cladosporium & & $0.76(n=1)$ & $0.44 \pm 0.09(n=2)$ & \\
\hline Penicillium & & $2.38 \pm 1.29(n=2)$ & $1.72 \pm 0.98(n=3)$ & \\
\hline Tricophyton & & $3.44 \pm 1.53(n=4)$ & $0.60 \pm 0.06(n=3)$ & \\
\hline
\end{tabular}

CRSwNP: Chronic rhinosinusitis with nasal polyps; HPF: High-power field; n: number of patients with detectable lgE levels ( $\geq 0.34$ UA/ml); *without asthma vs. with asthma; **mean \pm SD.

\section{Assessment of serum IgE levels after operation}

We assessed the levels of fungus-specific lgEs in the serum before and after operation. Blood tests for antigen-specific IgEs were performed for 4-24 months after operation.

\section{Statistics}

Fisher's exact test and Mann-Whitney $U$ test were used for comparisons among groups. Wilcoxon signed-rank test was used for within-group comparisons. Spearman correlation coefficients were calculated to assess the associations between patients' IgE levels and CT scores. A p - value $<0.05$ was considered significant.

\section{Results}

\section{Fungus-specific IgEs in the serum}

The detection rates of fungus-specific IgEs (Alternaria, Aspergillus, Candida, Cladosporium, Penicillium, and Trichophyton) in the serum were significantly higher in CRSwNP patients than in controls $(p<0.05)$. The incidence rate of fungus-specific $\lg E$ in the serum in CRSwNP patients was 23\% (25/111) (Table 2). The detection rate of fungus-specific lgE in the serum in CRSwNP patients with asthma $(11 / 40 ; 28 \%)$, was not significantly higher than that in the serum of CRSwNP patients without asthma $(14 / 71 ; 20 \%)$. The incidence rate of Candida-specific IgEs was the highest in the serum $(18 / 111 ; 16 \%)$. Incidence rates of Alternaria- and Aspergillus-specific IgEs in the serum were higher in 
Local total $\operatorname{IgE}$ level

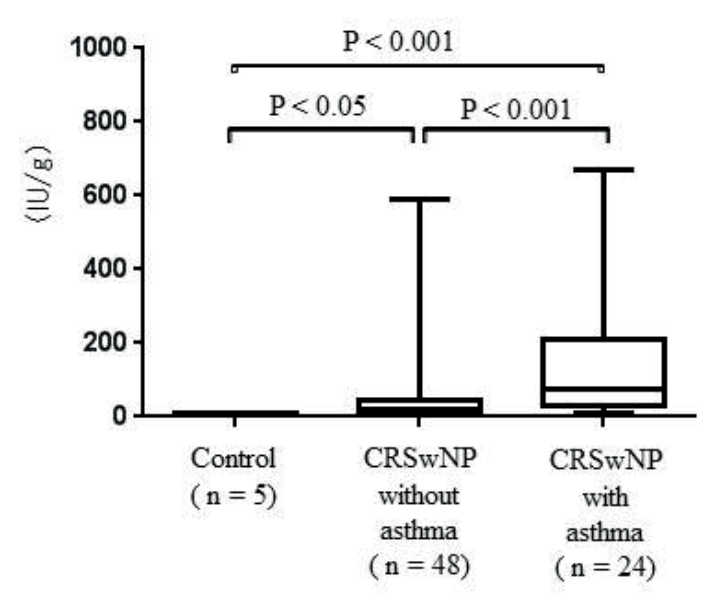

Local fungus-specific IgE level

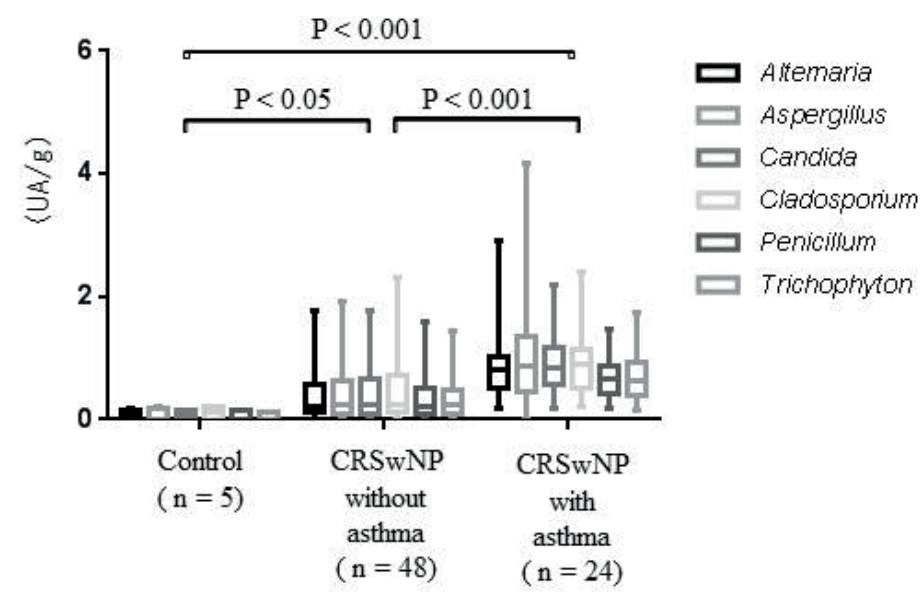

Figure 1. Local IgE levels. Total and antigen-specific lgE levels were significantly higher in CRSwNP patients than in controls $(p<0.05)$.

CRSwNP patients with asthma than in those without asthma. However, there were no significant differences in serum fungusspecific IgE levels between CRSwNP patients with $(n=11)$ and without asthma $(n=13)$.

\section{Total IgEs and antigen-specific IgEs in NPs}

In NPs, total IgEs and antigen-specific IgEs (against mites, Alternaria, Aspergillus, Candida, Cladosporium, Penicillium, Trichophyton, and SEB) were highly detected in CRSwNP patients (Table 3). In CRSwNP patients with NP IgEs, approximately all types of IgEs were detected. Total and antigen-specific lgE levels in NPs were significantly higher in CRSwNP patients than in controls $(p<0.05)$ (Figure 1). Total and antigen-specific lgE levels in NPs were significantly higher in CRSwNP patients with asthma than in those without asthma $(p<0.001)$. The detection rates of fungus-specific IgEs in NPs were significantly higher in CRSwNP patients with asthma than in those without asthma $(p=0.04)$. In CRSwNP patients, the levels of fungus-specific and total IgEs in NPs were significantly correlated $(p<0.001)$. Patients with fungus-specific IgEs in NPs showed higher levels of total IgEs in NPs than patients without fungus-specific lgEs in NPs $(p<$ 0.001). Fungus-specific IgEs were detected in 96\% (Aspergillus, 23/24) to $100 \%$ (Alternaria, Candida, Cladosporium, Penicillium, or Trichophyton; 24/24) of CRSwNP patients with asthma and in 69\% (Penicillium; 33/48) to 79\% (Alternaria; 38/48) of CRSwNP patients without asthma. In 79\% (11/14) of the CRSwNP patients with serum fungus-specific lgEs, the strain of fungus that showed the highest titers in the serum also showed the highest titers in NPs.

Correlation between IgE levels and CT scores in patients with CRSwNP
CT scores were significantly higher in CRSwNP patients with asthma than in those without asthma $(p<0.001)$ (Table 1). The levels of fungus- and SEB-specific lgEs as well as of total lgEs in NPs were significantly correlated with CT scores of CRSwNP patients with asthma (total lgE rs $=0.40$, Alternaria $\mathrm{rs}=0.46$, Aspergillus $\mathrm{rs}=0.42$, Candida $\mathrm{rs}=0.54$, Penicillium $\mathrm{rs}=0.58$, Trichophyton rs $=0.40$, and SEB rs $=0.43$ ) (Table 3 ). The levels of mite- and Cladosporium-specific IgEs in NPs were not significantly correlated with CT scores in CRSwNP patients with asthma. Additionally, the levels of fungus- and SEB-specific IgEs as well as of total IgE in NPs were significantly correlated with CT scores in CRSwNP patients without asthma (total lgE rs $=0.32$, Alternaria rs $=0.33$, Aspergillus $\mathrm{rs}=0.32$, Candida $\mathrm{rs}=0.33$, Cladosporium $\mathrm{rs}=0.31$, Penicillium $\mathrm{rs}=0.30$, Trichophyton $\mathrm{r}=0.30$, and SEB $r s=0.38)$. The correlation coefficients were higher in CRSwNP patients with asthma than in those without asthma. The levels of mite-specific IgEs in NPs were not significantly correlated with CT scores in CRSwNP patients without asthma. Moreover, the serum levels of total IgEs and IgEs specific to any of the above antigens, including fungi, were not significantly correlated with CT scores (data not shown).

\section{Fungal culture}

According to culture analysis, the detection rate of fungi in nasal secretions was $57.4 \%$ in CRSwNP patients and $66.7 \%$ in controls (Table 4). Overall, 49 and 23 genera of fungi were identified in samples from CRSwNP patients and controls, respectively (Tables 5 and 6). There were no significant differences in detection rates between CRSwNP patients with and without asthma. No specific fungal strains were detected in CRSwNP patients with asthma or without asthma. Fungi were detected upon PCR analysis of fungal colonies from the cultures, and strains were 
Table 3. Correlation between IgE levels in nasal polyps and CT scores of CRSwNP patients.

\begin{tabular}{|c|c|c|c|c|c|c|}
\hline & \multicolumn{3}{|c|}{ CRSwNP without asthma $(n=48)$} & \multicolumn{3}{|c|}{ CRSwNP with asthma $(n=24)$} \\
\hline & IgE levels & $\begin{array}{l}\text { Correlation } \\
\text { coefficient (rs) }\end{array}$ & P-value & IgE levels & $\begin{array}{l}\text { Correlation } \\
\text { coefficient (rs) }\end{array}$ & P-value \\
\hline Total lgE $(\mathrm{IU} / \mathrm{g})^{* *}$ & $476 \pm 129(n=41)$ & 0.3289 & 0.022 & $1550 \pm 369(n=24)^{*}$ & 0.4070 & 0.048 \\
\hline \multicolumn{7}{|c|}{ Specific $\lg E(U A / g)^{* *}$} \\
\hline Alternaria & $4.2 \pm 0.7(n=38)$ & 0.3398 & 0.018 & $8.4 \pm 1.1(n=24)^{*}$ & 0.4660 & 0.022 \\
\hline Aspergillus & $4.6 \pm 0.9(n=36)$ & 0.3269 & 0.023 & $10.3 \pm 1.8(n=23)^{*}$ & 0.4280 & 0.037 \\
\hline Candida & $4.8 \pm 0.9(n=37)$ & 0.3350 & 0.020 & $8.8 \pm 0.9(n=24)^{*}$ & 0.5415 & 0.006 \\
\hline Cladosporium & $5.2 \pm 0.1(n=37)$ & 0.3112 & 0.031 & $9.3 \pm 1.0(n=24)^{*}$ & 0.4028 & 0.051 \\
\hline Penicillum & $3.5 \pm 0.6(n=33)$ & 0.3008 & 0.038 & $6.6 \pm 0.6(n=24)^{*}$ & 0.5810 & 0.003 \\
\hline Trichophyton & $3.5 \pm 0.6(n=36)$ & 0.3060 & 0.034 & $6.7 \pm 0.7(n=24)^{*}$ & 0.4061 & 0.049 \\
\hline Mite & $7.1 \pm 1.3(n=42)$ & 0.2205 & 0.132 & $12.9 \pm 2.7(n=24)^{*}$ & 0.3848 & 0.063 \\
\hline SEB & $4.9 \pm 0.1(n=34)$ & 0.3857 & 0.007 & $7.0 \pm 0.7(n=24)^{*}$ & 0.4328 & 0.035 \\
\hline
\end{tabular}

CRSwNP: Chronic rhinosinusitis with nasal polyps; IgE: Immunoglobulin E; SEB: Staphylococcal enterotoxin B; $n$ : number of patients with detectable IgE levels; * $p<0.001$, without asthma vs. with asthma; ${ }^{* *}$ mean \pm SD.

Table 4. Fungal cultures from nasal secretions of patients.

\begin{tabular}{|c|c|c|c|c|}
\hline \multirow[t]{2}{*}{ Fungi } & \multicolumn{3}{|c|}{ Number of positive patients (\%) } & \multirow[t]{2}{*}{ P-value* } \\
\hline & $\begin{array}{l}\text { Control } \\
(n=24)\end{array}$ & $\begin{array}{l}\text { CRSwNP without asthma } \\
\qquad(\mathrm{n}=34)\end{array}$ & $\begin{array}{l}\text { CRSwNP with asthma } \\
\qquad(n=20)\end{array}$ & \\
\hline Total & $16(66.7)$ & $21(61.8)$ & $10(50.0)$ & 0.576 \\
\hline Alternaria & $1(4.2)$ & $1(2.9)$ & $0(0)$ & 0.766 \\
\hline Aspergillus & $3(12.5)$ & $3(8.8)$ & $2(10.0)$ & 0.732 \\
\hline Candida & $1(4.2)$ & $6(17.6)$ & $2(10.0)$ & 0.713 \\
\hline Cladosporium & $5(20.8)$ & $6(17.6)$ & $3(15.0)$ & 0.900 \\
\hline Penicillium & $9(37.5)$ & $4(11.8)$ & $1(5.0)$ & 0.732 \\
\hline Tricophyton & $0(0)$ & $0(0)$ & $0(0)$ & - \\
\hline Other ascomycetes & $7(29.2)$ & $10(29.4)$ & $5(25)$ & 0.972 \\
\hline Other basidiomycetes & $9(37.5)$ & $14(41.1)$ & $3(15)$ & 0.090 \\
\hline
\end{tabular}

CRSwNP: Chronic rhinosinusitis with nasal polyps; * without asthma vs. with asthma.

confirmed. The fungal strain isolated from nasal secretions did not coincide with that showing the highest level of fungusspecific lgEs in NPs (coincidence rate: $0 \%$ ).

Changes in serum fungus-specific IgE levels after operation Fungus-specific lgEs were detected in the serum of 25 patients with CRSwNP before operation; however, five of these patients were lost to follow-up. Fungus-specific IgEs became undetectable $(<0.34 \mathrm{UA} / \mathrm{ml})$ in the serum after operation in 6 of the 20 (30\%) patients with CRSWNP (Figure 2); this change was only observed in CRSwNP patients without asthma (6/11) but not in those with asthma. Of the five patients without asthma in whom fungus-specific IgEs remained detectable after operation, fungus-specific lgE levels decreased by approximately $30 \%$ in two patients. In two patients with asthma, fungus-specific lgE levels decreased after operation by approximately $25 \%$; however, fungus-specific IgE levels remained detectable in all patients with asthma. In patients whose fungus-specific IgE levels became undetectable after operation, the levels of fungus-specific IgEs in NPs and serum were significantly correlated (Figure 3). The levels of fungus-specific IgEs in NPs and serum were not significantly correlated in CRSwNP patients without negative changes in IgE levels after the operation. In patients with CRSwNP, the preoperative serum fungus-specific lgE levels of patients with negative changes in lgE levels after operation were not significantly lower (mean lgE levels: $1.7 \mathrm{UA} / \mathrm{ml}$ ) than those of patients without negative changes (mean lgE levels: $2.9 \mathrm{UA} / \mathrm{ml}$ ). In patients whose fungus-specific IgE levels became negative after operation, the levels of blood eosinophils decreased from $5.2 \%$ to $3.4 \%$. Among those in whom serum fungus-specific IgEs 
Table 5. Number of fungi in the nasal secretions of control subjects.

\begin{tabular}{|c|c|}
\hline Fungi & $\mathbf{N}(\%)$ \\
\hline Alternalia & $1(4.2 \%)$ \\
\hline Arthrinium & $1(4.2 \%)$ \\
\hline Aspergillus & $3(12.5 \%)$ \\
\hline A. aculeatus & 1 \\
\hline Aspergillus spp. & 2 \\
\hline Candida parapsilosis & $1(4.2 \%)$ \\
\hline Ceriporia lacerata voucher & $1(4.2 \%)$ \\
\hline Cladosporium & $5(20.8 \%)$ \\
\hline Cochliobolus & $1(4.2 \%)$ \\
\hline Cryptococcus & $3(12.5 \%)$ \\
\hline C. diffluens & 1 \\
\hline C. magnus & 2 \\
\hline Cystofilobasidiales & $1(4.2 \%)$ \\
\hline Fusarium & $4(16.7 \%)$ \\
\hline F. oxysporum & 3 \\
\hline Fusarium spp. & 1 \\
\hline Glomerellales & $1(4.2 \%)$ \\
\hline Guehomyces pullulans & $1(4.2 \%)$ \\
\hline Magnaporthe grisea & $1(4.2 \%)$ \\
\hline Malassezia restricta & $2(8.3 \%)$ \\
\hline Penicillium & $9(37.5 \%)$ \\
\hline P. glabrum & 1 \\
\hline P. thomii & 1 \\
\hline P. toxicarium & 1 \\
\hline Penicillium spp. & 6 \\
\hline Peniophora cinerea & $1(4.2 \%)$ \\
\hline Pleosporomycetidae & $1(4.2 \%)$ \\
\hline Rhodotorula & $2(8.3 \%)$ \\
\hline Sclerotiniaceae & $2(8.3 \%)$ \\
\hline Sporobolomyces carnicolor & $1(4.2 \%)$ \\
\hline Tilletiopsis washingtonensis & $1(4.2 \%)$ \\
\hline Trametes versicolor & $1(4.2 \%)$ \\
\hline Yarrowia lipolytica & $1(4.2 \%)$ \\
\hline
\end{tabular}

were detected, five CRSwNP patients showed serum IgEs against SEB before operation, and one patient exhibited a negative change in SEB-specific IgE after operation. Mite-specific lgEs were detected in 13 patients in whom serum fungus-specific IgEs were detected before operation; however, none became negative for mite-specific lgE after the operation.

\section{Discussion}

We analyzed fungi in nasal secretions and specific lgEs in the serum and NPs. Our results indicated that lgE levels in NPs but not in the serum were associated with the severity of paranasal inflammation. Moreover, the sinonasal mucosa might be a major

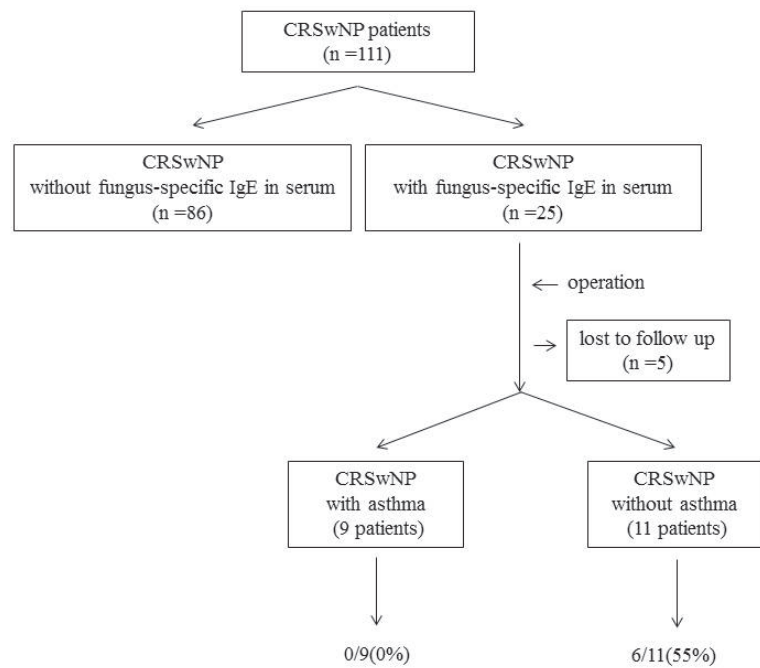

Figure 2. Negative changes of fungus-specific lgEs after operation. Fungus-specific lgEs in the serum became undetectable after operation in 6 of the 11 patients with chronic rhinosinusitis with nasal polyps without asthma.
CRSwNP patients with a negative change in the fungus-specific IgE levels after operation

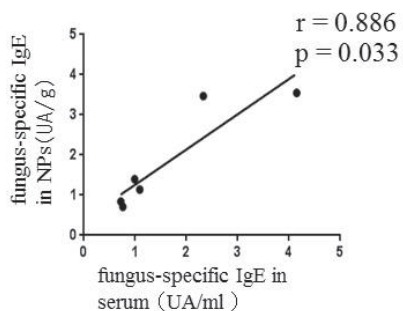

CRSwNP patients without a negative change in the fungus-

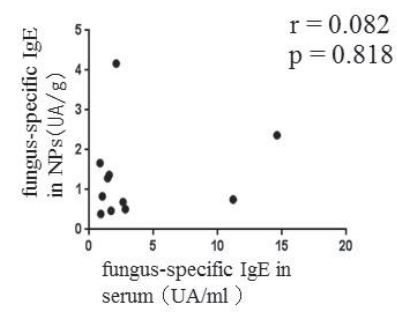
specific IgE levels after operation

Figure 3. Correlation between fungus-specific IgEs in the serum and nasal polyps. In patients whose fungus-specific IgE levels became negative after operation, the levels of fungus-specific lgE in the nasal polyps and serum were significantly correlated.

IgE-producing region in CRSwNP patients and the source of serum fungus-specific IgEs. These conclusions are based on the following observations. Fungus-specific IgEs were detectable in the serum of only approximately $20 \%$ of the examined patients with CRSwNP. However, fungus-specific IgEs were highly detectable in NPs of many CRSwNP patients with and without asthma. The levels of fungus- and SEB-specific IgEs as well as of total IgEs in NPs were significantly correlated with CT scores of CRSwNP patients. Moreover, fungus-specific IgEs became undetectable $(<0.34 \mathrm{UA} / \mathrm{ml})$ in the serum after operation only in CRSwNP patients without asthma (six of 11 patients) but not in with asthma. In patients whose fungus-specific lgE levels became negative after operation, the levels of fungus-specific lgEs in NPs and serum were significantly correlated.

Zhang et al. have observed mucosal tissue polyclonal lgEs in NPs ${ }^{(20)}$. In the present study, specific IgEs against various fungi and other aeroantigens, including SEB, were highly detectable 
Table 6. Number of fungi in the nasal secretions of patients with CRSwNP.

\begin{tabular}{|c|c|c|c|}
\hline Fungi & $N(\%)$ & Fungi & $\mathbf{N}(\%)$ \\
\hline Abundisporus sclerosetosus & $1(1.9 \%)$ & Fusarium merismoides & $1(1.9 \%)$ \\
\hline Acremonium & $1(1.9 \%)$ & Fuscopora & $2(3.7 \%)$ \\
\hline Alternaria & $1(1.9 \%)$ & Fusicladium & $1(1.9 \%)$ \\
\hline Arthrinium & $3(5.6 \%)$ & Hyphoderma transiens & $1(1.9 \%)$ \\
\hline Aspergillus & $5(5.6 \%)$ & Hydnochaete japonica & $1(1.9 \%)$ \\
\hline A. fumigatus & 1 & Lanspora & $1(1.9 \%)$ \\
\hline A. niger & 1 & Lodderomyces elongisporus & $1(1.9 \%)$ \\
\hline A. versicolor & 1 & Microporus xanthopus & $1(1.9 \%)$ \\
\hline Aspergillus spp. & 2 & Moniliella acetoabutans & $1(1.9 \%)$ \\
\hline Botryosporium & $1(1.9 \%)$ & Mycosphaerella & $1(1.9 \%)$ \\
\hline Candida & $8(14.9 \%)$ & Penicillium & $5(9.3 \%)$ \\
\hline C. albicans & 6 & Peniophora & $3(1.9 \%)$ \\
\hline C. glabrata & 1 & Periconiella & $1(1.9 \%)$ \\
\hline C. parapsilosis & 1 & Physisporinus vitreus & $1(1.9 \%)$ \\
\hline Capnodiales & $1(1.9 \%)$ & Pleosporales & $2(3.7 \%)$ \\
\hline Ceriporia lacerata & $1(1.9 \%)$ & Polyporales & $2(3.7 \%)$ \\
\hline Cladosporium & $9(16.7 \%)$ & Pseudozyma & $2(3.7 \%)$ \\
\hline Cochliobolus & $2(3.7 \%)$ & Phanerochaete & $2(3.7 \%)$ \\
\hline Coprinellus radians & $1(1.9 \%)$ & Rhodotorula slooffiae & $2(3.7 \%)$ \\
\hline Cordyceps bronginiartii & $1(1.9 \%)$ & Ramichloridium & $1(1.9 \%)$ \\
\hline Cyanotrama rimosa & $3(1.9 \%)$ & Ramularia & $1(1.9 \%)$ \\
\hline Cryptococcus & $4(7.4 \%)$ & Resinicium friabile & $1(1.9 \%)$ \\
\hline C. diffluens & 1 & Rhodotorula dairenensis & $1(1.9 \%)$ \\
\hline C. liquefaciens & 1 & Rigidoporus microporus & $1(1.9 \%)$ \\
\hline C. magnus & 1 & Trametes & $4(7.4 \%)$ \\
\hline C. neoformans & 1 & Trichoderma & $1(1.9 \%)$ \\
\hline Daedaleopsis confragosa & $1(1.9 \%)$ & Trichosphaeria pilosa & $1(1.9 \%)$ \\
\hline Diaporthe & $1(1.9 \%)$ & Tricosporon & $1(1.9 \%)$ \\
\hline Eutypella scoparia & $2(3.7 \%)$ & Verrucisporota & $1(1.9 \%)$ \\
\hline Filobasidium floriforme & $1(1.9 \%)$ & Zasmidium & $1(1.9 \%)$ \\
\hline
\end{tabular}

CRSwNP: Chronic rhinosinusitis with nasal polyps.

in NPs of many CRSwNP patients with and without asthma. Moreover, the levels of total IgE were correlated with the presence of fungus-specific IgEs in NPs. However, local IgEs were rarely detected in the turbinate mucosa. These results indicate that the presence of polyclonal IgEs in NPs does not contradict our findings. However, in $79 \%$ of the CRSwNP patients with positive serum fungus-specific lgEs in this study, the fungal strains that showed the highest titers in the serum and NPs coincided. Thus, both polyclonal IgE and monoclonal IgE production may occur in NPs. However, fungus-specific IgEs with the highest titers in NPs did not correlate with fungal strains detected in nasal secretions. Eosinophilic granule proteins, such as eosinophil-derived neurotoxins and major basic proteins, exhibit anti-fungal activi- ties ${ }^{(21)}$. The growth of infiltrating fungi in the sinonasal mucosa could be suppressed by the abundance of eosinophils. Therefore, eosinophil counts may explain the observed discrepancy between the strain with the highest fungus-specific IgE titer in NPs and the strain detected in nasal secretions.

Furthermore, mucosal tissue polyclonal lgE is functional in response to allergens ${ }^{(20)}$. In this study, the correlations between fungus-specific lgE levels in NPs and CT scores were weak. However, fungus-specific lgE levels in NPs but not in the serum were significantly correlated with the severity of CRS on CT in CRSwNP patients with and without asthma. This correlation was stronger in CRSwNP patients with asthma than in those without asthma. According to a previous report, local fungus-specific 
IgEs in NPs but not in the serum were associated with local eosinophilic inflammation in CRSwNP and AFRS (5). Thus, IgEs in NPs but not in the serum show a greater effect on local inflammation in CRSwNP patients with asthma than in those without asthma. A significant number of mast cells and elevated histamine and leukotrienes levels have been identified in NPs ${ }^{(22-24)}$. Anti-lgE treatment has been reported to improve symptoms and reduce the size of NPs ${ }^{(25-27)}$. According to previous reports, omalizmab could be a promising alternative option for CRSwNP patients with asthma ${ }^{(28,29)}$. Thus, IgE synthesis in NPs may play an important role in the development and aggravation of sinusitis.

In patients whose fungus-specific IgE levels became negative after operation, the levels of fungus-specific lgEs in NPs and serum were significantly correlated. These results indicate that the sinonasal mucosa comprises a major IgE-producing region in CRSwNP patients and is the source of serum fungus-specific IgEs. However, because few cases were assessed, further studies may be necessary to reach conclusions. Among the five CRSwNP patients without asthma who exhibited serum positivity for fungus-specific $\lg \mathrm{E}$, these $\lg \mathrm{Es}$ decreased in two patients but remained detectable after operation. Muñoz-Del-Castillo et al. have previously reported that $\sim 10 \%$ of the healthy individuals without any respiratory diseases, including sinusitis, were sensitized to fungi ${ }^{(30)}$; moreover, serum fungus-specific IgEs in these subjects may be produced in lymphoid tissues other than NPs. There was no remarkable reduction in serum fungus-specific IgEs after operation in any patient with asthma. Notably, in these patients, the lower airway has been suggested as another $\mathrm{IgE}$-producing region. The expression and production of IgEs in the lower airway have been reported ${ }^{(31,32)}$. Mite and SEB-specific IgEs were also highly detectable in NPs of patients with CRSwNP. There was no reduction in the titers of serum mite-specific IgEs after operation. SEB-specific IgEs were undetectable after operation in only one patient. Thus, the major site of IgE production may depend on the type of antigen and/or pathogenesis of the disease.
According to previous reports, atopic status with fungus-specific $\lg \mathrm{E}$ is one of the risks factors for adult-onset asthma ${ }^{(33)}$. Sensitization to Alternaria or Cladosporium but not to pollens or cats was found to be a significant risk factor for severe asthma ${ }^{(34)}$. Fungus-specific lgE levels were correlated with asthma severity (3). A new phenotype of asthma-severe asthma with fungal sensitization (SAFS) - has recently been described ${ }^{(35)}$. SAFS is diagnosed based on the presence of severe asthma and fungal sensitization and exclusion of allergic bronchopulmonary aspergillosis. Thus, a negative change or decrease in fungus-specific IgEs after operation may be a merit to reduce the risk and severity of asthma in CRSwNP patients.

\section{Conclusion}

In conclusion, this study showed that specific IgEs against various fungi are highly detectable in the NPs of CRSwNP patients. NPs and morbid sinus mucosa might constitute major lgEproducing regions, and fungus-specific IgEs in the serum may be derived from these NPs. Fungi may be involved in CRSwNP pathogenesis through the induction of Th2 immune responses, including IgE synthesis.

\section{Acknowledgements}

We are grateful to Dr. Takahashi and Dr. Kamikubo of Kimitsu Chuo Hospital as well as Dr. Yuza of Chiba Otolaryngology Surgical Center for sample collection.

\section{Authorship contribution}

Conception and design: YO, YO, TI, HY, SY, DS, and KK; Sample collection and preparation: $\mathrm{YO}$ and $\mathrm{Tl}$; Analysis and interpretation: YO, TI, TT, and MY; Drafting the manuscript for important intellectual content: TI and YO.

\section{Conflict of interest}

The authors declare that they have no conflicts of interest.

\section{References}

1. Fokkens WJ, Lund VJ, Mullol J, et al. European Position Paper on Rhinosinusitis and Nasal Polyps 2012. Rhinol Suppl. 2012(23):3 p preceding table of contents, $1-298$.

2. Van Bruaene N, Derycke L, Perez-Novo CA, et al. TGF-beta signaling and collagen deposition in chronic rhinosinusitis. J Allergy Clin Immunol. 2009;124(2):253-9, 9.e1-2

3. Matsuoka $H$, Niimi A, Matsumoto $H$, et al. Specific IgE response to trichophyton and asthma severity. Chest. 2009;135(4):898-903.

4. Fokkens WJ, Ebbens F, van Drunen CM. Fungus: a role in pathophysiology of chronic rhinosinusitis, disease modifier, a treatment target, or no role at all? Immunol
Allergy Clin North Am. 2009;29(4):677-88.

5. Matsuwaki Y, Uno K, Okushi T, Otori N, Moriyama H. Total and antigen- (fungi, mites and staphylococcal enterotoxins) specific IgEs in nasal polyps is related to local eosinophilic inflammation. Int Arch Allergy Immunol. 2013;161 Suppl 2:147-53.

6. Fokkens WJ, Lund V, Bachert C, et al. EUFOREA Consensus on Biologics for CRSwNP with or without asthma. Allergy. 2019

7. Kowalski ML, Agache I, Bavbek S, et al. Diagnosis and management of NSAIDExacerbated Respiratory Disease (N-ERD)-a EAACI position paper. Allergy. 2019;74(1):2839.

8. Staikūniene J, Vaitkus S, Japertiene LM
Ryskiene S. Association of chronic rhinosinusitis with nasal polyps and asthma: clinical and radiological features, allergy and inflammation markers. Medicina (Kaunas). 2008:44(4):257-65.

9. Tokunaga T, Sakashita M, Haruna T, et al. Novel scoring system and algorithm for classifying chronic rhinosinusitis: the JESREC Study. Allergy. 2015;70(8):995-1003.

10. Barham HP, Osborn JL, Snidvongs K, Mrad N, Sacks R, Harvey RJ. Remodeling changes of the upper airway with chronic rhinosinusitis. Int Forum Allergy Rhinol. 2015;5(7):56572.

11. Amin K. The Role of the T lymphocytes and Remodeling in Asthma. Inflammation. 2016;39(4):1475-82. 
12. Okano M, Kariya S, Ohta N, Imoto Y, Fujieda S, Nishizaki K. Association and management of eosinophilic inflammation in upper and lower airways. Allergol Int. 2015;64(2):131-8.

13. Anfuso A, Ramadan H, Terrell A, et al. Sinus and adenoid inflammation in children with chronic rhinosinusitis and asthma. Ann Allergy Asthma Immunol. 2015;114(2):10310.

14. Pawankar R, Zernotti ME. Rhinosinusitis in children and asthma severity. Curr Opin Allergy Clin Immunol. 2009;9(2):151-3.

15. Bent JP, Kuhn FA. Diagnosis of allergic fungal sinusitis. Otolaryngol Head Neck Surg. 1994;111(5):580-8.

16. Lund VJ, Mackay IS. Staging in rhinosinusitus. Rhinology. 1993;31(4):183-4.

17. Bakhshaee M, Fereidouni M, Nourollahian M, Movahed R. The presence of fungal-specific IgE in serum and sinonasal tissue among patients with sinonasal polyposis. Eur Arch Otorhinolaryngol. 2014;271(11):2871-5.

18. Song J, Wang $H$, Zhang YN, et al. Ectopic lymphoid tissues support local immunoglobulin production in patients with chronic rhinosinusitis with nasal polyps. J Allergy Clin Immunol. 2018;141(3):927-37.

19. Izawa K, Hijikata A, Tanaka N, et al. Detection of base substitution-type somatic mosaicism of the NLRP3 gene with $>99.9 \%$ statistical confidence by massively parallel sequencing. DNA Res. 2012;19(2):143-52.

20. Zhang N, Holtappels G, Gevaert P, et al. Mucosal tissue polyclonal lgE is functional in response to allergen and SEB. Allergy. 2011;66(1):141-8.

21. Yoon J, Ponikau JU, Lawrence CB, Kita H. Innate antifungal immunity of human eosinophils mediated by a beta 2 integrin, CD11b. J Immunol. 2008:181(4):2907-15.

22. Patou J, Holtappels G, Affleck K, et al.
Enhanced release of IgE-dependent early phase mediators from nasal polyp tissue. J Inflamm (Lond). 2009;6:11.

23. Takabayashi T, Kato A, Peters AT, et al. Glandular mast cells with distinct phenotype are highly elevated in chronic rhinosinusitis with nasal polyps. J Allergy Clin Immunol. 2012;130(2):410-20.e5.

24. Cao PP, Zhang YN, Liao B, et al. Increased local IgE production induced by common aeroallergens and phenotypic alteration of mast cells in Chinese eosinophilic, but not non-eosinophilic, chronic rhinosinusitis with nasal polyps. Clin Exp Allergy. 2014;44(5):690-700.

25. Gevaert P, Calus L, Van Zele $T$, et al. Omalizumab is effective in allergic and nonallergic patients with nasal polyps and asthma. J Allergy Clin Immunol. 2013;131(1):110-6.e1.

26. Penn R, Mikula S. The role of anti-IgE immunoglobulin therapy in nasal polyposis: a pilot study. Am J Rhinol. 2007;21(4):428-32.

27. Vennera MeC, Picado C, Mullol J, Alobid I, Bernal-Sprekelsen M. Efficacy of omalizum$a b$ in the treatment of nasal polyps. Thorax. 2011;66(9):824-5.

28. Tsetsos N, Goudakos JK, Daskalakis D, Konstantinidis I, Markou K. Monoclonal antibodies for the treatment of chronic rhinosinusitis with nasal polyposis: a systematic review. Rhinology. 2018;56(1):11-21.

29. Bidder T, Sahota J, Rennie C, Lund VJ, Robinson DS, Kariyawasam $\mathrm{HH}$. Omalizumab treats chronic rhinosinusitis with nasal polyps and asthma together-a real life study. Rhinology. 2018;56(1):42-5.

30. Muñoz-Del-Castillo F, Jurado-Ramos A, Soler $\mathrm{R}$, et al. Fungal sensitization in nasal polyposis. J Investig Allergol Clin Immunol. 2009;19(1):6-12

31. Balzar S, Strand M, Rhodes D, Wenzel SE. IgE expression pattern in lung: relation to sys- temic IgE and asthma phenotypes. J Allergy Clin Immunol. 2007;119(4):855-62.

32. Forester JP, Calabria CW. Local production of IgE in the respiratory mucosa and the concept of entopy: does allergy exist in nonallergic rhinitis? Ann Allergy Asthma Immunol. 2010;105(4):249-55; quiz 56-8.

33. Sunyer J, Antó JM, Kogevinas M, et al. Risk factors for asthma in young adults. Spanish Group of the European Community Respiratory Health Survey. Eur Respir J. 1997;10(11):2490-4.

34. Zureik M, Neukirch C, Leynaert B, et al Sensitisation to airborne moulds and severity of asthma: cross sectional study from European Community respiratory health survey. BMJ. 2002;325(7361):411-4.

35. Agarwal R. Severe asthma with fungal sensitization. Curr Allergy Asthma Rep. 2011;11(5):403-13.

Yoshitaka Okamoto, MD, PhD

Department of Otolaryngology

Head and Neck Surgery

Chiba University

1-8-1 Inohana

Chuo-ku

Chiba $260-8670$

Japan

Tel: $+81-43-226-2137$

Fax: $+81-43-226-3442$

E-mail: yokamoto@faculty.chiba-u.jp 